\title{
Microsociología, sociología sistémica y argumentación
}

\author{
Microsociology, Systemic Sociology and Argumentation
}

Sebastián Sayago

Pontificia Universidad Católica de Valparaíso, Escuela de Periodismo. Valparaíso, Chile. Correo electrónico: sebastian.sayago@ucv.cl

El presente artículo propone un estudio lingüístico de la argumentación con bases sociológicas. Parte de dos supuestos: a) la existencia de la argumentación obedece a un requisito de la organización social y b) la fundamentación sociológica de la argumentación puede ser hecha desde dos perspectivas, la microsociológica y la sistémica. El trabajo desarrolla los fundamentos de ambas perspectivas. Para la primera, cuyo eje teórico es el concepto de subjetividad, se retoman principalmente los aportes de E. Goffman y, para la segunda, cuyo eje teórico es el concepto de sistema/entorno, los de N. Luhmann. Una vez esbozada teóricamente la validez de ambas propuestas para la reconceptualización de la argumentación, se las retoma para analizar un mismo caso: una alocución de Iván Fuentes, el líder del Movimiento Social por la Región de Aysén, producida el 21 de marzo de 2012. Finalmente, se resumen los resultados obtenidos.

Palabras clave: argumentación, subjetividad, sistema social, sistema/entorno.

The following paper puts forward a linguistic approach to argumentation on sociological basis. It is based on two assumptions: a) the existence of argumentation follows a requirement of social organization, and $b$ ) the sociological basis of argumentation can be analyzed from two different perspectives, the microsociological and the systemic one. This work develops the grounds of both viewpoints. For the former, whose theoretical axis is the notion of subjectivity, contributions of E. Goffman are reintroduced, and, for the latter, whose theoretical axis is the notion of system/environment, N. Luhmann's proposal are taken into account. Once the validity of both perspectives has been theoretically sketched, an analysis of a single case has been made: the speech delivered on March $21^{\text {st }} 2012$ by Iván Fuentes, the leader of Movimiento Social por la Región de Aysén. Finally, a summary of the obtained results is presented.

Key words: argumentation, subjectivity, social system, system/environment.

\section{INTRODUCCIÓN}

Este trabajo ensaya un análisis argumentativo con base sociológica. Concretamente, intenta complementar aportes de la microsociología y de la sociología sistémica en el estudio de un mismo caso: la argumentación producida por el 
máximo dirigente de uno de los movimientos sociales más importantes de la historia reciente de Chile. Ese propósito general justifica el eclecticismo del marco teórico.

La propuesta parte de dos supuestos fundamentales. El primero es que la existencia de la argumentación en la comunicación humana obedece a un requisito de la organización social. Dicho de otra manera, la argumentación es un fenómeno originado por conflictos inherentes a la vida en sociedad. La aceptación de este postulado plantea la necesidad de explorar la naturaleza sociológica de la argumentación discursiva, es decir, cuáles son los aspectos de la organización social que la fundamentan como modo de expresión y de resolución de desacuerdos intersubjetivos.

El segundo supuesto es que esta fundamentación sociológica puede ser sostenida desde dos perspectivas, la microsociológica y la sistémica. Una permite encontrar la fuente de la argumentación en la instancia de la construcción social de la subjetividad y la otra, en la instancia de las relaciones entre sistemas.

Con el fin de demostrar que ambas perspectivas no son incompatibles entre sí y que, además, son valiosas para la línea de investigación trazada, se las desarrollará por separado para el análisis contrastivo de una alocución realizada en marzo de 2012 por Iván Fuentes, el principal líder del Movimiento Social por la Región de Aysén (en adelante, MSRA), una organización civil que durante varias semanas se enfrentó al gobierno chileno y que por su masividad y combatividad fue el primero en su tipo, desde el retorno a la democracia en 1990.

\section{FundAMENTOS TEÓRICOS}

\section{1. Aportes de la microsociología al estudio de la argumentación}

Bajo la denominación microsociología se agrupan estudios etnometodológicos, constructivistas e interaccionistas simbólicos, entre otros, todos los cuales centran la atención en las interacciones sociales y, como una consecuencia teórica, en las funciones sociales del lenguaje.

Entre los principales aportes que esta heterogénea corriente ha hecho al campo de los estudios lingüísticos, se destaca el modelo dramatúrgico de E. Goffman, expuesto principalmente en The P resentation of Self in Everyday Life (2004 [1959]), su primera monografía, y desarrollado en las trabajos posteriores (en especial, en Goffman 1979, 1981, 2001, 2006). El punto central de esta propuesta es la construcción social del self -sí mismo- en condiciones de incertidumbre. En The Presentation of Self..., el individuo es concebido como un agente compelido al desempeño de dos papeles básicos: actuante y per sonaje, siendo el primero "un inquieto forjador de impresiones" y el segundo, una figura evocada por la actuación (Goffman 2004: 268). Dado que este proceso de puesta en escena no está exento de tensiones, incongruencias y ardides, el lenguaje es utilizado como un importante recurso para el establecimiento del marco (frame) y el sostén de los papeles. Es uno de los elementos que permite mantener la coherencia de la fachada del individuo y preservar las interacciones rutinizadas con los equipos.

En Frame Analysis (2006 [1974]), Goffman profundiza en el estudio de la relación entre lo que se representa y lo que se interpreta en los encuentros sociales, haciendo hincapié en el proceso de definición de la situación. Para ello, problematiza 
el concepto de marco, entendido como "un dispositivo cognitivo y práctico de atribución de sentidos, que rige la interpretación de una situación y el compromiso en esta situación" (Goffman 2006: 63). Demuestra que estas operaciones de encuadre pueden ser problemáticas, lo que afecta la coherencia de la realidad construida. En F orms of Talk (1981), su última obra, también centra la atención en los encuentros sociales, prestando especial atención al uso del lenguaje. Propone concebir los actos lingüísticos como flujos sociales y plantea la conveniencia de complejizar los roles comunicativos de oyente y hablante. En su ya clásico capítulo 3, titulado "Footing" (1981: 124-157), Goffman concibe al oyente como una función que puede ser desempeñada tanto por los destinatarios del mensaje como por los oyentes no apuntados y los no previstos. Esta distinción le permite reconocer las posibilidades de situaciones comunicativas frecuentes, en las que no participan solamente un hablante y un oyente. También redefine el rol de hablante como una función que incluye tres papeles: el animador, el autor y el director. El animador es quien emite materialmente el mensaje, el autor, quien toma las decisiones de la elaboración textual (selección de sentimientos, ideas y palabras) y el director, quien asume la responsabilidad y la representación de las ideas y valores expresados. Retomando aportes de la sociolingüística, de la semántica generativa y de la teoría de actos de habla, Goffman propone un análisis de las emisiones (utterances) en el que se centre la atención en la expresión de sentimientos, ideas e intenciones, destinaciones, (auto)referencias, deixis, expresiones modales, cambio de código (code switching), entre otras cosas.

Vale apuntar que el análisis goffmaniano presupone una noción de sistema social que permite situar las acciones dentro de dominios de validez en cuyo interior el juego teatral, los marcos y los roles comunicativos tienen sentido. Este es un punto de contacto con la teoría luhmanniana, desde la cual se asume que las interacciones sociales son un tipo de sistema social, precario y más o menos efímero.

En otra corriente de la microsociología, pieza fundamental de la sociología del conocimiento de tradición fenomenológica, la famosa obra de P. Berger y Th. Luckmann La construcción social de la realidad (1993 [1966]) también resalta la importancia del lenguaje en las interacciones sociales, tanto para la manifestación de la subjetividad como para la construcción de "enormes edificios de construcción simbólica" que pesan sobre la realidad de la vida cotidiana como elaboraciones reificadas (Berger y Luckmann 1993: 59). A diferencia de Goffman, estos sociólogos no conciben el lenguaje solo como un instrumento de interacción estratégica, sino también como un recurso de ordenamiento social que presiona a los sujetos a adptarse a las posibilidades de expresión condicionadas por la gramática y a los campos semánticos ya establecidos, como una facticidad externa y coercitiva.

Al igual que en la teoría goffmaniana, subyace en la propuesta de Berger y Luckmann una visión sistémica de la realidad social. Sobre las interacciones sociales y las esferas institucionales, se yergue un universo simbólico que actúa como una matriz que garantiza el orden social, legitimando lo existente. Esta cristalización de sentidos compartidos propicia la operación de clausura intenta conjurar el peligro de la desintegración de la realidad social: "Toda realidad social es precaria; todas las sociedades son construcciones que enfrentan el caos" (Berger y Luckmann 1993: 134).

Otra conocida línea microsociológica que ha prestado atención al lenguaje como herramienta de construcción de realidad es la etnometodología. De su arsenal 
teórico, orientado al estudio de "las acciones como un continuo logro práctico de los miembros" (Garfinkel 2006 [1968]: 12), hay dos nociones particularmente útiles para reconocer las posibilidades abiertas por los mecanismos lingüísticos de significación: la indexicalidad y la reflexividad. El primero vincula el significado referencial con el contexto comunicativo y el segundo permite que los participantes se refieran a sí mismos, a sus prácticas y a la interacción en la que participan. Ambas nociones hacen posible la producción de un sentido situado y contingente que vuelve las acciones "racionalmente-visibles-y-reportables-para-todos-los-efectosprácticos" (2006:1). Esta concepción de autorreferencialidad también es un punto de contacto con la teoría de sistemas de Luhmann (1996, 1998, 2006), en tanto, desde la perspectiva del sociólogo alemán, un sistema social se constituye como tal cuando, mediante comunciación, puede generar un universo de sentido que permite tanto la autorreferencia como la heterorreferencia. Esta lectura fue desarrollada, entre otros, por Robles (2002), a partir del concepto denominado autopoiesis indexical.

Si bien las figuras de la microsociología mencionadas no se han detenido específicamente en la cuestión de la argumentación, sí han reflexionado sobre situaciones críticas en las que se cuestiona el cumplimiento de un rol o la validez de un conocimiento dado por sentado o, en términos generales, la coherencia de la realidad. El reconocimiento de aspectos problemáticos de la vida social está asociado a conceptos tales como motivación y propósito de la acción, rol, identidad social, creencias e imagen pública (self), los cuales configuran una noción compleja de sujeto. Varios de ellos aparecen presupuestos en las obras mencionadas (ocurre con los conceptos de motivación, propósito y creencias, en Berger y Luckmann 1993 y Garfinkel 2006, por ejemplo). Otros son objeto de rigurosos análisis (rol e identidad social, en Berger y Luckmann 1993 y Goffman 1971, 1979, 2001, etc., e imagen pública en toda la obra goffmaniana).

Con el fin de componer un modelo que articule con coherencia todas estas categorías teóricas y las oriente al análisis de la argumentación, se propone una noción de sujeto compuesta por las siguientes dimensiones:

a) motivaciones y propósitos: se entiende por motivaciones las causas psicológicas que impulsan la comunicación y por propósitos, los fines que definen la organización de un plan comunicativo;

b) roles: papeles o conductas estereotipadas;

c) identidades sociales: representaciones sociales del sujeto producto de su (auto) inclusión en un grupo determinado;

d) sistemas de creencias compartidas: conjuntos de representaciones compartidas dentro de cada grupo o dentro de la organización social;

e) imagen pública: la representación dramatúrgica del sí-mismo (self) en la interacción social.

Estas categorías establecen una perspectiva de análisis que permite retomar conceptos ya establecidos en el campo del análisis del discurso en general y en el campo de los estudios de la argumentación en particular. Así, por ejemplo, la primera dimensión (motivación y propósitos) puede incluir el fenómeno de la dialogía (Bajtín 1982; Voloshinov 1992), dado que no hay motivaciones ni propósitos que surjan en una instancia aislada y puramente individual. Al contrario, estos son respuestas a discursos previos y tienen sentido en contextos discursivos particulares. La dimensión de los roles puede incluir las nociones de proponente, oponente y tercero, 
con los que Ch. Plantin (1998a, 1998b) modela la situación argumentativa. También se puede incluir aquí la cuestión de la destinación múltiple propia de los discursos políticos (Verón 1987; García Negroni 1988; García Negroni y Zoppi Fontana 1992). La dimensión de las identidades sociales puede incluir las identidades grupales, tal como las conciben T. van Dijk $(1999,2008)$ y E. Laclau $(1996,2005)$. A pesar de las diferencias teóricas, en ambas propuestas se plantea una relación diferencial mediante la que se constituye un nosotros opuesto a un ellos. En la dimensión de los sistemas de creencias pueden incorporarse los desarrollos que de este concepto realizan $\mathrm{T}$. van Dijk (1999, 2008) o A. Raiter $(1999,2002,2003) .{ }^{1}$ Por último, la dimensión de la imagen pública puede ser tomada como el resultado visible (representado) de la integración dinámica de todas las dimensiones anteriores.

Como se intentará demostrar en el análisis, esta noción de sujeto permite reconocer el conflicto argumentativo en diferentes dimensiones de la subjetividad.

\subsection{Aportes de la sociología sistémica al estudio de la argumentación}

En algunas tradiciones teóricas suele pensarse que la microsociología está reñida con la sociología sistémica, sobre todo cuando se vincula a esta última con la macrosociología (Salles 2001; Beltrán 2005). Sin embargo, las diferencias entre ambas perspectivas pueden ser consideradas como una cuestión de énfasis. Tal como se apuntó anteriormente, el estudio de los encuentros intersubjetivos presupone una organización sistémica de las relaciones que generan el sentido necesario para la construcción de la realidad social.

Continuando con esta senda expositiva, se expondrán los aportes que, al estudio de la argumentación, puede hacer la propuesta de sociología sistémica más sólida y reputada de la actualidad, elaborada por N. Luhmann (1996, 1998, 2006, etc.). $\mathrm{Su}$ postulado de partida es que la sociedad no se compone de seres humanos, sino de procesos de comunicación. En este contexto teórico, las nociones antropológicas de individuo, actor o sujeto, son reemplazadas por una noción de sujeto constituido por un sistema psíquico que tiene como entorno un sistema orgánico. Se denomina persona al sujeto cuando este es tomado como objeto de observación por un sistema psíquico diferente o por un sistema social (Luhmann 1998 [1984]: 117-120). La relación que une al sistema psíquico y al sistema social también es de sistema/ entorno. Los sistemas psíquicos se ubican en el entorno de los sistemas sociales.

Ambos son sistemas autopoiéticos, es decir, sistemas con la capacidad de revisar y generar estructuras internas tomando como referencia su relación con el entorno. Los sistemas psíquicos utilizan los procesos de conciencia para diferenciarse del entorno y reproducirse. De este modo, se constituyen a sí mismos. Análogamente, los sistemas sociales utilizan procesos de comunicación, mediante los cuales pueden autoobservarse y autodescribirse, posibilitando así su reproducción.

Tanto los procesos de conciencia como los de comunicación son autorreferenciales: permiten que el sistema se represente a sí mismo como algo diferente de su entorno. El

Conviene consignar que, mientras, para el primero, el sistema de creencias es el producto de la ideología, entendida como una base axiomática (van Dijk 2008: 204), para el segundo, es "un mecanismo biológico de construcción de representaciones mentales a partir de estímulos (en principio, lingüísticos)" (Raiter 2003: 151). Cualquiera de estas dos opciones teóricas es compatible con la noción de sujeto que aquí se plantea, ya que ambas suponen un mecanismo regulado de producción de representaciones de la realidad. 
procesamiento de la autorreferencialidad y de la complejidad constituye una experiencia de sentido, en tanto supone la actualización constante de posibilidades de existencia y de relación. El sentido le indica al sistema que todo podría ser de otro modo.

Un sistema autopoético, entonces, es lo que es porque reconoce el complejo juego de diferencias en el que participa. Estas diferencias, propone Luhmann, pueden ser agrupadas en tres dimensiones del sentido: la objetiva, la temporal y la social.

En la dimensión objetiva, todo comienza con una primera disyunción. El sistema percibe una diferencia mínima y todavía indeterminada, que actúa como un estímulo para la realización de una exploración hacia adentro y hacia afuera. Este doble horizonte, interior y exterior, actúa como un entramado de remisiones donde eso que existe, la cosa, encuentra su lugar y adquiere su sentido. En la dimensión temporal, las remisiones se efectúan entre el horizonte del pasado y el horizonte del futuro. En este espacio se distinguen la reversibilidad y la irreversibilidad de los procesos. La dimensión social establece la diferencia entre Ego y Alter, entendidos como horizontes de perspectivas distintas, las cuales pueden ser compatibilizadas entre sí o no. Se configura así la tensión entre consenso y disenso.

A partir de estas categorías y de acuerdo con los objetivos de este trabajo, es posible replantear el lugar de lo argumentativo en la organización social. Aquí se concebirá la argumentación como una de las respuestas del sistema ante un entorno siempre complejo e incierto. Es un modo de interacción (de interpenetración, en términos de Luhmann) que se asienta principalmente en la dimensión social, exacerbando el disenso. El sistema manifiesta algún grado de desacuerdo respecto de un estado de cosas en el entorno y, para ello, tiene la posibilidad de recurrir a la argumentación como un mecanismo para intentar controlar la inestabilidad y la amenaza.

Este disenso puede ser especificado a través de las dimensiones espacial y temporal. Se argumenta acerca de algo que existe fuera del sistema: un acontecimiento, otro sistema, un discurso, una representación que del propio sistema se tiene en ese exterior constitutivo. Mediante las operaciones de autorreferencia y heterorreferencia, la comunicación argumentativa plantea la posibilidad de establecer si el conflicto remite a algo que está dentro del sistema o en su entorno. La determinación del error tiene proyección en la dimensión del tiempo, ya que está acompañada de la expectativa por sus consecuencias para comportamientos futuros.

El juego de posibilidades y expectativas no debe conducir a la suposición de que la argumentación es o deba ser siempre racional y que conduzca siempre hacia un acuerdo de partes. La argumentación existe porque promueve la promesa del acuerdo a través del uso del lenguaje y no porque efectivamente cumpla esa promesa.

Para el análisis, se complementarán las categorías sociológicas de la teoría luhmanniana con categorías discursivas comunes a los enfoques microsociológicos (en particular, las expresiones deícticas).

\section{Metodología y CORPuS}

La metodología utilizada en este trabajo es dialéctica, en tanto explota un proceso de constante ida y vuelta entre la instancia de la construcción teórica y la instancia de la operación empírica (Samaja 1994; Sayago 2007). El punto de inicio del estudio está situado en la praxis vital del autor, instancia en la que se asignó preliminarmente relevancia teórica y social al problema. En cuanto a la primera, se seleccionó/ 
construyó un caso que permitiera explorar la complementariedad de los aportes provenientes de la microsociología y de la sociología sistémica al estudio de la argumentación. Debía tratarse de una puesta de escena comunicativa suficientemente compleja como para reconocer una historia y diferentes indentidades en el discurso analizado. La instrumentación del criterio de relevancia social otorgó prioridad al movimiento social más importante de la primera mitad del año 2012 en Chile (país donde se desarrolló este trabajo): el MSRA.

El análisis que aquí se presenta está centrado en un evento discursivo particular: la conferencia de prensa dada por el líder más destacado, Iván Fuentes, el 21 de marzo de 2012, antes de ser recibido por un representante de la Presidencia de la Nación. La primera parte de esta conferencia consistió en la alocución de Fuentes y la segunda, en un diálogo con los periodistas. El corpus está constituido por la alocución. ${ }^{2}$

\section{Presentación del caso}

El lunes 6 de febrero de 2012, un grupo de gremios de la región de Aysén se reunió para lanzar públicamente la convocatoria a un movimiento social amplio en reclamo de mejores políticas de parte del Estado nacional. Dos días después, nació el MSRA, constituido sobre la base de una cadena de equivalencias (Laclau 1996, 2005) que se sintetizaba en una identidad social novedosa (los patagones) y un slogan muy efectivo (Tu problema es mi problema). Articulaba las demandas socioeconómicas, sanitarias, educativas, laborales y ambientales, entre otras, muchas de las cuales preexistían a la fundación del MSRA como reclamos aislados de sectores particulares.

El gobierno central no dio las respuestas esperadas, por lo que, en la región, se multiplicaron las movilizaciones y, luego, los cortes de ruta. Con la llegada de Fuerzas Especiales de Carabineros el 15 de febrero, comenzaron a vivirse días de gran tensión, dado que la fuerza policial desarrolló prácticas, primero, de intimidación y, luego, de represión.

Tras varias semanas de negociaciones frustradas y con el creciente interés de la opinión pública nacional, el jueves 22 de marzo llegó a Santiago una delegación del MSRA para reunirse en La Moneda con el Vicepresidente Rodrigo Hinzpeter, máximo representante del gobierno nacional en ausencia del Presidente Sebastián Piñera. La delegación fue recibida por diferentes organizaciones sociales en la sede de la Asociación Nacional de Empleados Fiscales (ANEF). En esa oportunidad, Fuentes protagonizó una de las conferencias de prensa de mayor impacto social de los últimos años en Chile. ${ }^{3}$

Para hacer el análisis, se hizo una transcripción de la versión transmitida por Televisión Nacional de Chile. Dado que el análisis está focalizado en los recursos argumentativos, se optó por una transcripción normalizada, es decir, adecuada a las pautas normativas del español estándar. Esto no supuso, en ningún caso, la sustitución de vocablos ni el cambio de sentido de lo dicho. La normalización consistió en el pasaje de la oralidad a las convenciones de la escritura (segmentación de cláusulas, agregado de signos de puntuación y de exclamación, uso de comillas para las citas, etc.).

3 Para ilustrar este efecto, se cita la caracterización hecha por El M ostrador (22/03/2012), uno de los diarios online de mayor consumo en Chile:

"Antes de llegar al Palacio de La Moneda para reunirse con el Vicepresidente de la República, Rodrigo Hinzpeter, el 


\section{ANÁLISIS}

\subsection{El análisis de la argumentación desde una perspectiva microsociológica}

Antes de su aparición en la sede de la ANEF, Iván Fuentes había sido convertido en un personaje central de las noticias referidas al conflicto en la Región de Aysén. Sus características más superficiales concordaban con el estereotipo de un pescador artesanal del sur del país: un hombre adulto (44 años de edad), de estatura más bien baja, padre de familia, con educación secundaria incompleta, con el rostro curtido y el cabello desaliñado, dueño de una voz aguda y de baja intensidad, vestido casi siempre con la misma chaqueta azul.

Sin embargo, en esa primera conferencia de prensa en Santiago, quedó de manifiesto que Fuentes también tenía cualidades que no se circunscribían al estereotipo del humilde y rústico pescador artesanal de la Patagonia. Era muy seguro y muy fluido al hablar, variaba adecuadamente el tono, combinaba una gran cantidad de estrategias argumentativas (ejemplo, metáfora, pregunta retórica, reformulación, estilo directo, estilo indirecto y estilo indirecto libre, cambios estratégicos en la persona gramatical y en el alcance referencial de cada una, etc.).

Se puede reconocer en la alocución de Fuentes la manera en que modeló socialmente los componentes del sujeto argumentador que puso en escena. A continuación, se las retomará en el orden en que fueron expuestas en 1.1:

\section{a) Motivación y propósito}

El discurso de Fuentes construyó un sujeto colectivo que, explotando la reflexividad de la comunicación, expresa dos motivos para la interacción social. El primero, es la necesidad de manifestar el agradecimiento por el recibimiento en Santiago. El segundo, la necesidad de explicar la validez de sus reclamos. Ambos motivos definen el propósito general de la comunicación.

El primer motivo es explicitado en el inicio de la alocución:

(1) Nada. Decirles que para nosotros es un orgullo estar acá. Primero que nada... La primera sensación que tenemos es de agradecimiento. Queríamos expresárselo así, en forma directa, a todas las organizaciones sociales, a todos aquellos que sienten el sentido de manada, el sentido de cardumen, esa necesidad de juntarnos. Eso es lo que nos hace más grandes.

La manifestación del motivo permite, a la vez, la construcción de un sujeto afectivo y la caracterización del estilo utilizado. Fuentes pone en escena a un grupo, el de los 15 representantes del MSRA, que estaba presente frente al auditorio, integrado por otras organizaciones sociales y por periodistas, y dota a ese grupo de la capacidad de

vocero del Movimiento Social por Aysén, Iván Fuentes, ofreció en la sede de la ANEF una emotiva conferencia de prensa que no pasó desapercibida para el gobierno por las dotes comunicacionales con las que se lució el dirigente. "Es un discurso social potente, no sólo por lo 'cuñero' de sus frases, sino que por su capacidad de argumentar, es un cañón comunicacional", reconoció más de algún asesor de Palacio que escuchó sus argumentos sobre las demandas de la región patagónica.

"Fuentes hizo una alocución espontánea, sin la ayuda de papeles y menos de "torpedos", que estuvo cargada de la emotividad, cercanía y franqueza que ya quisiera para sí cualquier político." 
experimentar sentimientos (orgullo, agradecimiento, sentido de manada, necesidad de juntarse). Esta motivación justifica la definición del estilo discursivo mediante un recurso indexical: primero, el marcador deíctico que señala un modo presentado como evidente para todos ("así") y, luego, la nominación ("en forma directa").

La manifestación de los sentimientos tiene un destinatario específico que no coincide exactamente con quienes están en la ANEF: son "las organizaciones sociales" y "todos aquellos que sienten el sentido de manada, el sentido de cardumen". Mediante la enumeración, el sujeto colectivo realiza una escalada en el alcance del destinatario: se pasa de las organizaciones que apoyaron al MSRA a cualquier chileno que experimente ese particular sentido de la unión. El recurso de la escalada finaliza con la construcción de un nosotros inclusivo de extensión máxima: "Eso es lo que nos hace más grandes".

La segunda motivación, la necesidad de validar sus reclamos, amplía el propósito comunicativo inicial. Ese sujeto colectivo que el hablante fue construyendo y que incluyó a todos los chilenos es nuevamente reespecificado en una secuencia argumentativa que se sostiene en cuatro conceptos clave: sintonía, respeto, paz social y dolor ajeno, los cuales actúan como signos ideológicos (Voloshinov 1992), en tanto expresan valoraciones ideológicas de un grupo social determinado por su situación subordinada y por el conflicto con el grupo dominante. Los signos ideológicos forman parte de un campo semántico humanitario, enraizado en el universo simbólico de la sociedad (retomando los conceptos de Berger y Luckmann 1993). Sin embargo, el locutor resignifica estos conceptos como justificación de la lucha política, al sostener que debe darse la sintonía dentro del nosotros, para luego poder sintonizar "con los otros, con los que tienen el poder". En este punto, la expresión de agradecimiento da paso al pedido de unidad estratégica en una relación de confrontación.

En la descripción de la realización de este componente de la subjetividad, resalta también la dialogía. Apenas comenzadas las movilizaciones en Aysén, el gobierno había acusado a sus dirigentes de haber roto la paz social. Entonces, Fuentes justifica la solicitud de apoyo refutando este discurso cuyo conocimiento está presupuesto. Por un lado, afirma que hay que respetar el entorno y aclara que habla "del aire, de los ríos, de las aguas". Esta referencia remite al proyecto de la represa HidroAysén, fuertemente resistido por los ciudadanos de la Patagonia (y de otras regiones de Chile también). Por otro lado, afirma que hay que respetar a "la gente simple, la gente que vive en el último rincón de la Patagonia". Acusa a "los que tienen el poder" y a "los ricos" de faltar este doble respeto y de ser los responsables del conflicto, pero lo hace de un modo indirecto, neutralizando las identidades en conflicto: "la verdad es que se va perdiendo la paz social cuando nos tornamos insensibles al dolor ajeno, cuando nos distanciamos de los otros y cuando ganar plata es lo más importante". Esta descripción se atribuye a un nosotros de cortesía, pero, en el contexto en que se produce este discurso, se sobreentiende que está asignada a los otros.

De este modo, explotando la empatía, la dialogía y los sobreentendidos, Fuentes completa la manifestación del propósito de su alocución.

\section{b) Roles}

En la situación comunicativa, Fuentes desempeña el rol de animador y de autor, pero no el de director (Goffman 2006), ya que se encarga de construir una 
responsabilidad colectiva de las ideas expresadas. No plantea conflictos entre estos roles. Incluso, se esfuerza por mantener discursivamente la identidad colectiva a través del uso del nosotros (como ya vimos, un nosotros que se va resignificando en el desarrollo de la alocución).

El discurso de Fuentes construye otro rol: el del adversario político. Las distintas identidades sociales articuladas son utilizadas como fuente de legitimación de la lucha contra el gobierno y contra los poderosos. El MSRA es el adversario del establishment político, el actor que, ya oficialmente reconocido, reclama y exige lo que otros actores políticos (sobre todo, los partidos de la oposición) no quieren o no pueden reclamar y exigir. El rol de adversario se expresa en la destinación múltiple del discurso, mediante la que se construye un contradestinatario (el gobierno y los capitalistas), un paradestinatario (los chilenos en general) y un prodestinatario (un colectivo heterogéneo que incluye al MSRA, a los aiseninos, a los trabajadores) (Verón 1987).

\section{c) Identidades sociales}

El discurso de Fuentes puso en escena varias identidades colectivas. Todas ellas organizadas en torno a la oposición básica Nosotros vs. Ellos (van Dijk 1995, 1999). Por un lado, Ios delegados del M SRA, Ios ayseninos, los habitantes de la Patagonia, los pobres, el pueblo; por otro, los ricos, los grandes capitalistas y el gobierno. Las identidades del Nosotros son articuladas por un criterio de marginalidad y de clase que nunca es del todo explícito. Se detalla una marginalidad espacial ("la gente que vive en el último rincón de la Patagonia, la gente que vive en el último rincón del campo") para representar una marginalidad social y política: a esta gente no se la consulta y no se la respeta. Estas identidades subordinadas son también desagregadas y articuladas mediante enumeración:

(2) La pagas bien a tu nana, le pagas bien a tu trabajador, le pagas bien a tu gente, le pagas bien a los mineros, le pagas bien a los campesinos, le pagas bien a los pescadores artesanales...

En esta secuencia se va de un hipónimo (nana), a un hiperónimo (trabajador), a un término más vago (gente) y, finalmente, a otros hipónimos (mineros, campesinos, pescadores artesanales). El paralelismo sintáctico posibilita un paralelismo semánticodiscursivo (todos estos actores deben trabajar para recibir a cambio una manutención de parte del capitalista). De este modo, se esboza una cadena equivalencial abierta (Laclau 1996, 2005), en la que todo trabajador asalariado podría sentirse incluido.

Mediante diferentes estrategias, Fuentes representa al grupo adversario. Primero, como ya se vio, de un modo indirecto define a los dominadores como un actor colectivo carente de sensibilidad. Luego, utiliza el estilo indirecto libre para atribuirle una visión de mundo ridiculizada:

(3) Simplemente yo y mañana cambio el auto y me compro otro, último modelo. Y pasado mañana sale otro y le cambio, porque quiero cambiarlo simplemente de color.

También utiliza una destinación directa paródica. En el pasaje que sigue a la enumeración ya analizada, Fuentes dice: 
(4) Entonces, tú puedes tener plata y vivir tranquilo. Pero, en el escenario donde unos pocos ganan mucho y otros muchos siguen sufriendo, ¿qué es lo que pasa? Tenís que ponerle cuatro cercos a tu casa y tenís que comprar perros Rottweiler y tenís que protegerte. La verdad es que eso no es vida.

Este tipo de destinación es compleja. Por un lado, apunta a un destinatario particular, al que se ridiculiza con el fin de desprestigiarlo ante el auditorio y con el de reforzar la complicidad con este. Por otro lado, permite presentar una opinión como universalmente válida (como en enunciados de la clase 'Cuando ocurre $\mathrm{X}$, uno se siente mal / tú te sientes mal').

Pero Fuentes no planteó una contradicción irresoluble, ya que expresa de diferentes maneras que los dos grupos pueden convivir en un estado de equilibrio, referido a través de las expresiones "paz social", "sociedad armoniosa", "vivir bien", "vivir en igualdad de condiciones".

En tres momentos de la alocución, Fuentes abandona la primera persona del plural para pasar a la primera del singular con sentido autorreferencial: cuando define el concepto respeto al entorno (5), cuando plantea expectativas acerca del desarrollo de la alocución (6) y, ya cerca del final, cuando aclara que él no está familiarizado con las nuevas tecnologías de la comunicación (7):

(5) Así lo hemos dicho hace largo rato ya. Pero con dos cosas muy importantes: con respeto al entorno y, cuando hablo del entorno, no hablo simplemente de la soja, hablo del aire, de los ríos, de las aguas, y, cuando hablo con respeto a los lugareños, hablo de la gente simple, la gente que vive en el último rincón de la Patagonia, la gente que vive en el último rincón del campo. Nosotros decimos: “¡Respeto a los lugareños!”.

(6) Entonces, ¿por qué se va perdiendo la paz social? Espero no alargarme mucho, pero la verdad es que se va perdiendo la paz social cuando nos tornamos insensibles al dolor ajeno.

(7) [...] nos apoyaron, nos mandaron twitters, los jóvenes que se manejan con la computación, yo no, sin embargo, le agradecemos desde el corazón a todos ustedes la potencia que han puesto para que los medios de comunicación también puedan tener la otra perspectiva.

En el primer caso, es un desplazamiento entre la identidad social del MSRA (director) y su identidad como portavoz (autor) que afecta principalmente la representación de la autoridad que legitima la definición de un concepto. Este desplazamiento no resulta conflictivo porque el nosotros referido al MSRA introduce la necesidad de las definiciones y después las retoma, haciéndolas suyas. En el segundo caso, expone su identidad como autor, anticipando la complejidad de la explicación que dará acerca de la pérdida de la "paz social". El tercer caso de uso de la primera persona es más interesante, porque Fuentes pone en escena una identidad deteriorada con el fin de diferenciarse de los jóvenes que apoyaron el MSRA a través de los twitters. De esta manera, refirma su pertenencia a ese colectivo mayor denominado "gente simple". Este desplazamiento, más breve que el anterior, tiene lugar durante el cierre de la alocución, cuando reitera los agradecimientos de parte de todo el MSRA. 


\section{d) Sistemas de creencias compartidas}

El discurso de Fuentes expone una visión de la realidad en la que se combinan una concepción clasista y una visión humanista. El planteo clasista se refleja en el antagonismo fundamental definido por la relación dominante/dominado, tratada como equivalente del par capitalistas/trabajadores. De los diferentes pasajes en que este planteo se hizo manifiesto, fue en el último en el que la contundencia fue mayor:

(8) [...] nosotros decimos que, con sentido de manada, con sentido de cardumen, somos muchos más que los seis u ocho capitalistas de este país.

Por el tono enfático con que fue emitida, por su carácter de conclusión, por ser el enunciado que disparó la mayor ovación del auditorio, por ser la frase que mejor satisfacía las expectativas mediáticas y políticas que pesaban sobre la alocución de Fuentes, es comprensible que fuera la cita más destacada de toda la conferencia de prensa.

El planteo humanista se expresa en el deseo de un capitalismo humanizado, un orden social ideal, propuesto por Fuentes como la instancia superadora del conflicto. Veamos el siguiente ejemplo:

(9) A ver, ¿por qué la gente humilde tiene que odiar a los ricos? ¿Por qué los ricos se distancian de los pobres? ¿Es que acaso no nos necesitamos?

Es un pasaje muy interesante, por la riqueza de la información presupuesta y sobreentendida (Kerbrat-Orecchioni 1986). Se presupone:

-la existencia de la gente humilde y de los ricos,

-el odio de la gente humilde hacia los ricos,

-el distanciamiento de los ricos respecto de los pobres.

Se sobreentiende:

-la equivalencia entre la gente humilde y los pobres;

-la tendencia casi inevitable (naturalizada) en los pobres a la experimentación de odio hacia los ricos, algo que puede remitir bien a la envidia o bien al rencor de clase; -la tendencia de los ricos a distanciarse de los pobres, lo que remite bien a la indiferencia o bien al desprecio.

El discurso de Fuentes permite ambas interpretaciones de la relación afectiva entre los pobres y los ricos: hay envidia de unos e indiferencia de otros, o hay rencor de clase de unos y desprecio de otros. Tanto lo sobreentendido como lo presupuesto forma parte del sentido común (Raiter 2003) de parte de la sociedad chilena.

La pregunta por la necesidad, formulada de manera negativa y con el marcador discursivo acaso, que indica el grado de la circunstancia referida, está orientada hacia la respuesta positiva. Esa necesidad que une a los pobres y a los ricos es tanto humana como clasista. La necesidad humana se refiere a la sensibilidad por el dolor ajeno, la necesidad clasista -menos explícita en la alocución- al mantenimiento de un trabajo asalariado que permita "vivir bien", es decir, "vivir en una sociedad armoniosa".

En esta representación de la realidad social, no se cuestiona tampoco la lógica del sistema democrático representacional. En el discurso de Fuentes se critica al gobierno por no atender las demandas del pueblo, pero se acepta el rol del Estado como último garante de la paz social y de la justicia: 
(10) Entonces, queremos que el Estado de Chile, que es en definitiva el padre de todos los chilenos, el que tiene que repartir las lucas, el Estado de Chile tiene que hacer una política más de hermanos, una política más igualitaria.

Mediante una analogía con la relación familiar, coloca al Estado en el rol de padre y a los ricos y a los pobres como los hijos entre los que debe distribuir los recursos con sentido de igualdad.

e) I magen pública

La imagen pública de Fuentes y del grupo de delegados que él representa es el producto de la integración dinámica de todos los componentes anteriormente analizados. Esta imagen pública recibe los atributos dados directa e indirectamente por el mismo discurso que la construye. De manera directa, este sujeto colectivo se autodescribe positivamente, por ejemplo, representando la humildad como un lugar en el que se habita y desde el cual se habla:

(11) La verdad es que, desde el sentimiento más humilde de la Patagonia, nosotros decimos que hay que recuperar esa sintonía.

La atribución indirecta se realiza a través de la exhibición in situ de las virtudes. El sujeto colectivo reclama mayor humanismo y, en su discurso, se muestra humano, sensible, afectivo; afirma representar a la "gente simple" y el discurso mismo exhibe un lenguaje poblado de metáforas que reelaboran sentidos de la vida cotidiana de la "gente simple".

En cada uno de los componentes de la subjetividad puesta en escena se manifiesta el conflicto argumentativo. Hay un nosotros que da argumentos orientados a desestimar la posición del ellos. Si encuadramos el proceso discursivo global dentro de la situación argumentativa tipificada por Plantin (1998a, 1998b), el MSRA es el proponente, porque es quien rompe el statu quo con sus demandas, y el gobierno el oponente, porque es quien las cuestiona. Pero, si tratamos de hacer lo mismo con esta conferencia de prensa particular, no es tan simple asignar los roles, porque ya hay varios argumentos y contraargumentos intercambiados, los cuales forman parte de las condiciones de producción de la presencia de los delegados en Santiago y de la alocución de Fuentes. Desde el punto de vista del sujeto discursivo, los argumentos del gobierno son contraargumentos sobreentendidos.

\subsection{El análisis de la argumentación desde una perspectiva sistémica}

Analizaremos en la alocución de Fuentes tomando como eje el par sistema/ entorno. Nos valdremos también de otras categorías luhmannianas, tales como el sentido, la autorreferencia y la heterorreferencia.

a) I ván $\mathrm{F}$ uentes

Con la denominación I ván F uentes, designamos una persona, es decir, un conjunto de expectativas más o menos estables acerca del comportamiento de un ser humano 
dado. La descripción de Fuentes hecha en el apartado anterior es, entonces, un detalle de nuestras expectativas en tanto observadores.

Ahora bien, la alocución que aquí se analiza es una respuesta de Iván Fuentes, en tanto sistema psíquico, ante un entorno complejo, en el que reconoce: otras personas (otros sistemas psíquicos observados por él), el sistema social correspondiente a la delegación del MSRA, el sistema social correspondiente al MSRA, los sistemas sociales correspondientes a otras organizaciones sociales (la ANEF, la FECH, etc.), el sistema de medios de comunicación de masas, el sistema político y el sistema jurídico, entre otros. Todos estos sistemas que están situados dentro de su entorno son filtrados por un criterio de relevancia que permite dar prominencia a algunos y dejar a los otros en el fondo.

El discurso de Fuentes evidencia la relevancia que otorga a la delegación del MSRA y, principalmente, al propio MSRA. La mayoría de las autorreferencias son grupales, lo que demuestra el intento de disimular la frontera interior/exterior que lo separa de ambos sistemas sociales.

Como ya se señaló, Fuentes realiza tres autorreferencias individuales (en los pasajes 5, 6 y 7). Se puede inferir que la primera presenta una relación armónica con los dos sistemas sociales y que esta se manifiesta en las tres dimensiones de sentido. La segunda, en cambio, presenta una relación parcialmente conflictiva. En la dimensión espacial, asume que hay un proceso exterior que desconoce (los "twitters", "la computación") pero que asume como socialmente valioso. En la dimensión temporal, al asociarlo a "los jóvenes", está situando el dominio de esas tecnologías en relación con la distinción pasado/futuro. Él se ubica en el primer término, fuera de la sociedad de la hipercomunicación que avizora. Sin embargo, en la dimensión social, la relación con ese entorno no es conflictiva: los jóvenes han utilizado estas modalidades de comunicación para apoyar la lucha del MSRA, es decir, de gente como él.

Entonces, solo la segunda autorreferencia señala la existencia de un entorno relativamente incierto y amenazante.

Desde un nivel estrictamente lingüístico, cada una de las dimensiones del sentido y los modos de autorreferencia y heterorreferencia pueden ser descritos mediante el análisis de los marcadores deícticos y de expresiones que, dentro de las representaciones discursivas construidas, hagan referencia a la relación sistema/entorno. A modo de ejemplo, se retoma el pasaje (5), con las autorreferencias subrayadas:

(5') Así lo hemos dicho hace largo rato ya. Pero con dos cosas muy importantes: con respeto al entorno y, cuando hablo del entorno, no hablo simplemente de la soja, hablo del aire, de los ríos, de las aguas, y, cuando hablo con respeto a los lugareños, hablo de la gente simple, la gente que vive en el último rincón de la Patagonia, la gente que vive en el último rincón del campo. Nosotros decimos: “¡Respeto a los lugareños!”.

La autorreferencia grupal construye el marco para la autorreferencia individual. El discurso presenta un nosotros (el MSRA) responsable de la realización de una acción pasada que, al estar formulada en Pretérito Perfecto Compuesto, tiene efectos que se extienden hasta el presente en que se sitúa la alocución (tal como lo propone para el español rioplatense García Negroni 1999). Se implica que eso que se dijo en el pasado tiene existencia en el presente: es algo dicho, es decir, materializado objetivamente por el lenguaje. El adverbio ya, refuerza esa relación entre el pasado y el presente. La 
autorreferencia individual mantiene la representación de una acción verbal (hablar), pero formulada en Presente ("cuando hablo del entorno"). Lo interesante de este uso es que permite tanto una interpretación atemporal como una deíctica. En el primer caso, la acción es habitual y se sobreentiende que es realizada repetidamente durante una pasado cuya duración puede concordar con el de la existencia de lo dicho por el MSRA. En el segundo caso, designa solo una acción realizada en el momento en que se realiza la alocución.

Mediante una heterorreferencia, el discurso también construye un sistema localizado en la lejanía, es decir, en un punto remoto del entorno espacial compartido por todos los presentes en la ANEF: "la gente que vive en el último rincón de la Patagonia, la gente que vive en el último rincón del campo". Esa distancia física indefinida entre esta "gente" y Fuentes es la que legitima su autoridad de portavoz, de representante. Implícitamente, está afirmando que tanto él como esos pobladores existen en el entorno de un subsistema del sistema político que los ignora: el gobierno. Esa existencia se manifiesta en las tres dimensiones del sentido: están lejos (dimensión espacial), han dicho cosas (dimensión temporal) y disienten, porque quieren que se los respete (dimensión social).

\section{b) EI MSRA}

El impacto social de Iván Fuentes en tanto persona se debe al modo en que transmite el discurso del MSRA y al contenido de este discurso (contenido que él contribuye a dar no solo por su rol de portavoz, sino, sobre todo, por el de líder).

La alocución explota las tres dimensiones del sentido. En la objetiva, la distinción interior/exterior es utilizada para elaborar varias representaciones del conflicto. La más importante es la de la relación Región de Aysén/resto de Chile (sobre todo, la zona central, donde está Santiago). Esa frontera define una situación interna de múltiples carencias objetivas porque ese exterior constitutivo es hostil.

El MSRA está presente (a través de sus delegados) en Santiago. El desplazamiento espacial hace que ese exterior opresivo sea provisoriamente el interior y que Aysén quede provisoriamente en el exterior. Entonces, mediante el uso del lenguaje, este sistema social enfatiza su pertenencia a esa interioridad lejana: "la Patagonia", "la dignidad de la Patagonia", "el último rincón del campo".

La construcción espacial de la oposición entre el interior y el centro, entre los dominados y los dominantes tiene su correlato en la dimensión temporal. Ese sistema social de límites difusos que, por momentos, pone en escena Fuentes y que incluye tanto a la Región de Aysén como a toda la clase trabajadora, tiene un pasado descrito como una acumulación de frustraciones:

(12) Decimos: "Amo a esta tierra que me vio nacer y lucharé por su gente y su futuro". Ese eslogan lo escuchamos siempre, ¿cierto? Y, entonces, pero tiene que haber el discurso a conciencia, pero detrás de eso tiene que ser conciencia y ley. La ley en Chile hay que arreglarla, la ley en chile hay que renovarla.

Ese pasado crea las condiciones de posibilidad de la disputa actual. El MSRA también tiene un pasado, al que recurre para demostrar la coherencia de su postura: "Y hemos hecho un trabajo desde hace largo rato", "Así lo hemos dicho hace largo rato ya". 
El transcurso del tiempo espesa la gravedad de la demanda, porque todo sistema social (al igual que todo sistema psíquico) asume que es un flujo irreversible y toda pérdida es, de algún modo, irrecuperable.

La tercera dimensión del sentido, la social, permite al MSRA expresar las relaciones de consenso y de disenso. Las primeras posibilitan la representación de un sistema social amplio que incluye a muchos subsistemas. Ese proceso de integración puede extenderse hasta incluir a todo Chile, pero, para ello, tiene que eliminarse el disenso, que es causado por el sistema político, el sistema económico y el sistema legal. El gobierno (subsistema político) no regula debidamente el sistema económico (en particular, el desarrollo del capitalismo) y no instrumenta leyes que protejan adecuadamente ni a los sistemas sociales con menos recursos, ni al medioambiente.

Así como mediante las continuas autorreferencias, el MSRA representa sus vínculos con la lejanía, el pasado y la necesidad de consenso, mediante las heterorreferencias representa los vínculos con los sistemas que lo apoyan (a los que integra en un sistema mayor, mediante el nosotros) y con los que los enfrentan (situados siempre en el entorno). La entidad sistémica de ese nosotros dinámico refiere alternativamente:

al MSRA,

al MSRA + la Región de Aysén,

al MSRA + el auditorio de la ANEF,

al MSRA + la Región de Aysén + el auditorio de la ANEF.

En el entorno de estos, hay cuatro sistemas destacados: el político, el legal, el de medios de comunicación de masas y Chile, que es presentado como el sistema más amplio, el que está en el entorno de todos. Dentro del sistema político, el MSRA distingue entre el subsistema de gobierno y el subsistema estatal y responsabiliza al primero de no permitir que el segundo administre justicia. También lo acusa de desestimar el reclamo del MSRA: "Escuchábamos a algún ministro que decía: 'Es que van a vivir mejor que los santiaguinos, es que van a vivir mejor que la gente de la Octava Región'. No se trata de eso. Se trata de vivir en igualdad de condiciones".

El sistema legal, relacionado funcionalmente con el sistema político, también forma parte de ese entorno hostil que rodea al MSRA y a la Región de Aysén: "La Ley de Pesca, que es muy buena para la Primera, la Segunda, la Tercera Región, a nosotros nos hace mal".

Tanto el sistema de gobierno como el sistema legal son presentados a través de percepciones del entorno. En el primer caso, a través de un discurso que se escucha; en el segundo, a través de una imposición que daña.

En ese entorno complejo y dinámico, estos sistemas se interpenetran y negocian las representaciones sociales dominantes. Uno de esos sistemas sometido a presiones es el sistema de medios de comunicación de masas, el especializado en la observación de segundo orden de la sociedad. Su función, afirma Luhmann (2000), es irritar la moral social, exponer los asuntos que resultan socialmente preocupantes. Y, según el MSRA, la acción de los sistemas que le dieron su apoyo logró dar relevancia a este conflicto y fomentar la difusión del discurso de los ayseninos (ver pasaje 7).

Como ya se apuntó, todas estas relaciones intersistémicas representadas discursivamente pueden ser registradas lingüísticamente por los marcadores deícticos 
y otras expresiones referidas a entidades y procesos cuya ubicación respecto de la delimitación sistema/entorno sea relevante.

La construcción social de la persona Iván Fuentes y la construcción discursiva del MSRA son procesos que se determinan recíprocamente y que dependen, claro, de los procesos de conciencia del sistema psíquico Iván Fuentes. Su alocución presenta rasgos marcadamente argumentativos, lo que se justifica por la intención manifiesta de modificar aspectos del entorno que son percibidos como negativos para la continuidad y el desarrollo del sistema afectado.

El análisis permitió reconocer también la alocución de Fuentes como un instrumento para la autopoiesis del MSRA, un sistema social que se constituye a sí mismo mediante el uso del lenguaje.

\section{Conclusiones}

El trabajo efectuado consistió en un análisis de una misma argumentación desde dos perspectivas que enfatizan aspectos diferentes de la sociedad: la microsociología y la sociología sistémica.

La primera permitió reconocer el conflicto argumentativo en cada uno de los componentes de la subjetividad propuestos: a) la motivación y el propósito, b) los roles, c) las identidades sociales, d) el sistema de creencias compartidas y c) la imagen pública. La segunda lo situó en la distinción sistema/entorno.

Si bien las dos perspectivas esbozadas difieren en los ejes de análisis, no son incompatibles entre sí. Comparten una concepción de realidad según la cual la comunicación es el pilar fundamental para la sociedad. Coinciden también en asumir la diferenciación como una operación constitutiva. La microsociología (sobre todo en su versión goffmaniana) propone una diferenciación teatralizada, según la cual los actores tienen la posibilidad de exagerar o de disminuir las diferencias entre ellos y los otros participantes de los encuentros sociales. Tienen, además, la posibilidad de tematizarla reflexivamente. La sociología sistémica luhmanniana sostiene que el establecimiento de la diferencia es el primer paso de la autopoiesis y, por ello, los sistemas de sentido desarrollan mecanismos de autorreferencia y de heterorreferencia.

La diferenciación es clave también para la situación argumentativa básica, ya que esta se configura como tal cuando un actor presume que la validez de su discurso es cuestionada por un discurso diferente.

La alocución de Iván Fuentes ejemplifica claramente este juego de distinciones y expone, además, otra noción fundamental: la contingencia. Por un lado, su discurso representa un estado de cosas que puede y debe cambiar. Por otro, representa un entorno complejo, en el que encuentra solidaridades pero también hostilidad. Esta es la instancia en la que se inscribe la argumentación y se crean las condiciones de posibilidad para la acción política.

El análisis de la alocución de Iván Fuentes demostró también que los abordajes desde la perspectiva microsociológica y desde la perspectiva sistémica pueden compartir un menú de categorías frecuentemente utilizado en los estudios lingüísticos de argumentación (léxico valorativo, destinación múltiple, deixis, variación referencial, la resignificación, etc.). Es decir, hay una fuerte complementariedad teórica en diferentes puntos. 
Para finalizar, este trabajo tiene un carácter explotatorio y los resultados obtenidos deben ser considerados como líneas para revisar y profundizar. Su mayor fortaleza reside en la idea que lo anima: la argumentación es un modo de comunicación ante la incertidumbre provocada por la precariedad de la realidad.

\section{OBRAS CITADAS}

Beltrán, Miguel. 2005. "El dilema: Acción y estructura. Una visión desde Jeffrey Alexander y Anthony Giddens". Revista Colombiana de Sociología 2: 251-271. Disponible en: http://www.revistas.unal.edu.co/index.php/recs/article/viewFile/11303/11961. [Fecha de consulta: 11 de junio de 2011].

Berger, Peter y Luckmann, Thomas. 1993. La construcción social de la realidad. Buenos Aires: Amorrortu.

García Negroni, María Marta. 1988. "La destinación en el discurso político: una categoría múltiple". Lenguaje en Contexto 1(1/2): 85-111.

. 1999. "La distinción Pretérito Perfecto Simple / Pretérito Perfecto Compuesto. Un enfoque discursivo". Discurso y Sociedad 1(2): 45-60.

García Negroni, María Marta y Zoppi Fontana, Mónica. 1992. Análisis lingüístico y discurso político. Buenos Aires: CEAL.

Garfinkel, Harold. 2006. Estudios en Etnometodología. Barcelona: Anthropos. [1968].

Goffman, Erving. 1979. Relaciones en público. Microestudios de orden público. Madrid: Alianza. . 1981. F orms of talk. Filadelfia: University of Pennsylvania Press. 2001. Estigma. La identidad deteriorada, Buenos Aires: Amorrortu. 2004. La presentación de la persona en la vida cotidiana. Buenos Aires: Amorrortu. 2006. F rame Analysis. Los marcos de la experiencia Madrid: CIS.

Kerbrat-Orecchioni, Catherine. 1986. L'implicit. París: Armand Colin.

Laclau, Ernesto. 1996. Emancipación y diferencia. Buenos Aires: Ariel. 2005. La razón populista. Buenos Aires: Fondo de Cultura Económica.

Luhmann, Niklas. 1996. Introducción a la teoría de sistemas. México: Universidad Iberoamericana. 1998. Sistemas sociales. Barcelona: Anthropos. 2000. La realidad de los medios de masas, Barcelona: Anthropos. 2006. La sociedad de la sociedad. México: Herder.

Plantin, Charles. 1998a. La argumentación. Barcelona: Ariel. . 1998b. "La interacción argumentativa". Escritos, Revista del Centro de Ciencias del Lenguaje 17-18: 23-49.

Perelman, Chaïm y Olbrechts-Tyteca, Lucie. 1989. Tratado de la argumentación. La nueva retórica. Madrid: Gredos. [1958].

Raiter, Alejandro. 1999. Lingüística y política. Buenos Aires: Biblos. . 2002. Representaciones sociales. Buenos Aires: Eudeba. 2003. Lenguaje y sentido común. Buenos Aires: Biblos.

Robles, Fernando. 2002. "Sistemas de interacción, doble contingencia y autopoiesis indexical". Cinta de Moebio 15. Disponible en: http://www2.facso.uchile.cl/publicaciones/ moebio/15/robles.htm [Fecha de consulta: 13 de mayo de 2009].

Salles, Vania 2001. "El debate micro y macro: Dilemas y contextos", Perfiles Latinoamericanos 18: 115-151. Disponible en: http://redalyc.uaemex.mx/pdf/115/11501806.pdf [Fecha de consulta: 5 de junio de 2011].

Samaja, Juan. 1994. E pistemología y metodología. Buenos Aires: Eudeba.

Sayago, Sebastián. 2007. "La metodología de los estudios críticos del discurso. Problemas, posibilidades y desafíos", en P. Santander Molina (ed.), Discurso y crítica social, Valparaíso, PUCV. 
Toulmin, Stephen. 2007. Los usos de la argumentación, Barcelona: Península. [1958, 2003].

Van Dijk, Teun. "Semántica del discurso e ideología". Discurso \& Sociedad 2(1): 201-261.

[1995]. Disponible en: http://www.dissoc.org/ediciones/v02n01/DS2\%281\%29Van\%20 Dijk.html. [Fecha de consulta: 17 de mayo de 2010]. . 1999 Ideología. Barcelona: Gedisa.

Van Eemeren, Frans y Grootendorst, Rob. 1992. Argumentation, Communication and Fallacies. A Pragma-Dialectal Perspective. Nueva York y Londres: Lawrence Erlbaum. 2011. U na teoría sistemática de la argumentación. Buenos Aires: Biblos.

Verón, Eliseo. 1987. "La palabra adversativa". E. Verón et al., El discurso político. Buenos Aires: Hachette.

Voloshinov, Valentin. 1992. El marxismo y la filosofia del lenguaje. Madrid: Alianza. 